\title{
基于点云和倾斜摄影测量的融合数据自动构建城市建筑三维模型 方法的研究
}

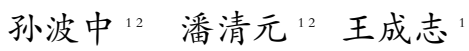

1 天水三和数码测绘院有限公司 2 甘肃省测绘工程技术研究中心

DOI:10.32629/gmsm.v3i3.695

[ 摘 要] 在高楼林立的城市, 由倾斜摄影测量技术生成的三维模型都会由于近地面缺失数据出现拉花甚至失真现象。本文在倾斜摄影测量数据 的基础上,融合车载移动测量系统Trimble MX8获取的建筑立面点云数据,共同构建城市建筑三维模型,有效地解决了拉花问题,并进一步提出这 种作业方法的不足及下一步研究方向。

[关键词] 倾斜摄影测量；车载移动测量；点云；城市实景三维建模

\section{引言}

随着 “数字城市” “智慧城市” 建设的不断深入, 以及 “实景三维中国 建设”项目的即将启动, 城市三维模型这一核心建设内容显得越来越重要, 其生产技术近年来虽在不断发展革新, 从传统手工建模到三维点云半自动 建模再到倾斜摄影测量自动建模, 作业效率越来越高, 但模型的精细程度 却有所降低。单一的建模技术都存在着明显的优势和劣势, 不能既保障模 型的精细程度又保证其生产效率, 因此, 需要结合不同技术优势, 改进作业 方法, 从而得到一种较好的解决方案。

\section{1 车载移动测量和倾斜摄影测量技术}

车载移动测量技术是从 20 世纪 90 年代逐步发展起来一种快速、高效、 无地面控制点的测绘技术, 它集成了激光测距、近景摄影测量、GNSS定位 及惯性导航等技术, 是当前测绘领域最前沿的科技之一。由于它具有快速 性、非接触性、穿透性、主动性、高密度和高精度等特性, 被广泛应用于 大比例尺地形测绘、三维建模、街景地图服务、兴趣点 (POI) 采集、市政 部件普查、道路资产清查、道路病害检测、地质灾害排查和土方量计算等 领域。

倾斜摄影测量技术是目前国际摄影测量领域中一项较为新颖的技术， 其系统主要由飞行控制系统、POS系统、相机组组成, 它区别于传统垂直航 空摄影测量技术, 可同时从垂直、倾斜等不同角度对地进行影像采集, 不仅 能够真实的反映建筑物顶部的信息, 同时也能从侧面角度观测到建筑物的 立面信息, 获取建筑物更为完整的信息。因此, 它被广泛应用于5D (DEM、 DOM、DLG、DRG、DMI) 产品生产、地籍测绘、三维建模、应急指挥、灾害 评估、规划设计等领域。

倾斜摄影测量技术虽然能快速获取到建筑物顶部及立面信息, 但由于 近地面地物遮挡严重, 比如紧密相邻建筑之间的相互遮挡、行道树的遮挡, 缺失有效数据, 从而造成城市建筑三维模型在近地面出现拉花、失真等问 题。车载移动测量技术能获取到建筑的立面信息, 但不能获取到建筑顶部 信息。两者的数据既能相互补充, 又都是通过点云构建三角网来实现自动 建模, 这就给它们融合构建完整建筑三维模型提供了可能。

\section{2 融合处理建模关键步骤和方法}

2. 1 总体技术流程

车载点云数据和倾斜摄影测量数据融合处理建模主要是通过坐标 转换将点云和倾斜影像数据转换成统一坐标系, 再将点云数据融合到 倾斜摄影处理过程中自动生成的点云数据中, 两者共同构建 TIN, 再将 纹理自动映射到模型上即可得到完整的建筑模型。其总体技术流程如 图1所示:

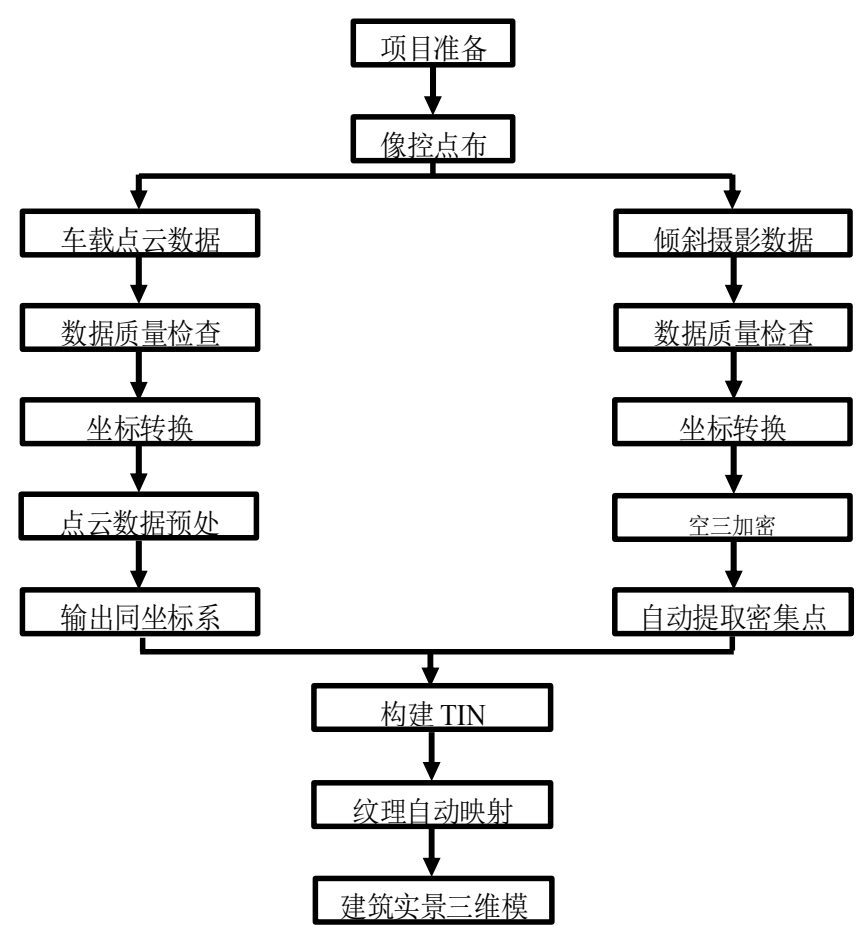

图1 点云和倾斜摄影测量数据融合处理构建三维模型的总体技术流程 2. 2 像控点布测

为了使倾斜摄影测量得到精度较高的点云数据, 要提前布设像控点, 采用罐装喷漆喷绘三角标志 (如图2), 像控点四周要平坦, 不能有太大的 高程变化, 不能有高大地物遮挡, 如树木、高楼等。在像控点布设时, 兼 顾车载点云控制点及坐标转换同名点布设, 这样能保障用相同控制点对 点云数据进行校正, 从而保障两类数据保持相同精度, 以及采用相同同 名点进行坐标转换, 保障坐标转换精度。在布设控制点的同时采用 GPS-RTK获取其坐标。

2. 3数据采集处理

(1) 数据采集。(1)车载点云数据采集。由于城市道路两边都会有行道 树遮挡, 在进行车载点云数据获取时, 采用往返扫采集建筑立面数据, 最大 程度获取到全面的建筑立面数据。(2)倾斜摄影数据采集。在采集倾斜摄影 数据时, 要选择合适的航飞时间, 确保有足够的光照度和能见度, 以便使影 像清晰, 颜色饱和, 色彩鲜明, 色调一致, 从而保障建筑的纹理与实际地物 一致。 
(2) 坐标转换。车载点云数据的坐标转换和倾斜摄影数据的坐标转换 都是根据同名点求取相应的七参数, 从而使数据能够处于统一的坐标系 下。要注意的是, 在求取七参数的时候需要了解软件采用的转换模型, 转换 模型不同, 所求的七参数会有很大差别。一般情况下, 大多软件使用布尔沙 模型, 但也有个别软件使用其他模型, 如莫洛金斯基模型。本文所用的车载 点云数据处理软件采用的是莫洛金斯基模型, 而倾斜摄影POS数据的坐标 转换采用的却是布尔沙模型, 因此, 需要分别求取七参数。

(3) 数据处理。(1)车载点云数据预处理。车载点云数据预处理包括POS 数据解算、点云数据轨迹校正、点云数据解算、点云数据校正和点云数据 输出五大步骤。在点云数据轨迹校正时, 需要输入数据采集日期。由于我 国时间与美国有 8 小时时差, 因此若采集数据时是上午八点之前开始的, 则 需要输入前一天的日期, 否则就会出现时间不符问题。(2)倾斜摄影数据处 理。倾斜摄影数据处理就是利用专业软件 (如ContextCapture Center、 Pixe1 Factory、Street Factory等) 进行空三自动化加密, 以航飞影像为 原始数据, 结合相机检校参数和高精度的定位定姿POS数据, 通过自动匹配 相关影像产生自动匹配点, 利用光束法区域平差, 检查匹配点及自动剔除 超限匹配点, 同时在标准点位少点区域进行人工加点, 保证平差时要求的 最少点数, 最终解算加密点坐标及外方位元素。它主要包括加密分区、相 对定向、绝对定向、加密接边四大步骤。

为了数据处理效率以及降低对硬件性能的需求, 在数据处理时, 需要 进行分区处理。为了保障最终成果精度, 一定要保证各个环节的误差不能 超限, 而且尽可能提高每个环节的精度。

(4) 三维模型构建。利用合格的空三加密成果自动生成的密集点云, 再融合车载点云数据, 共同构建不规则三角网 TIN, 从而自动生成建筑白模, 再将倾斜影像的纹理自动映射到白模上, 即可得到建筑实景三维模型。

\section{3 结果分析}

本文采用ContextCapture Center软件将倾斜摄影测量数据和车载点 云数据进行融合处理并构建三维模型, 下图显示了利用倾斜摄影测量数据 和融合数据分别构建的三维模型。通过对比可知, 倾斜摄影测量数据融合 车载点云数据后, 有效地补充了建筑立面缺失的数据, 房檐底部及建筑近 地面的拉花问题得到有效解决, 模型更真实, 更能反映实际情况。

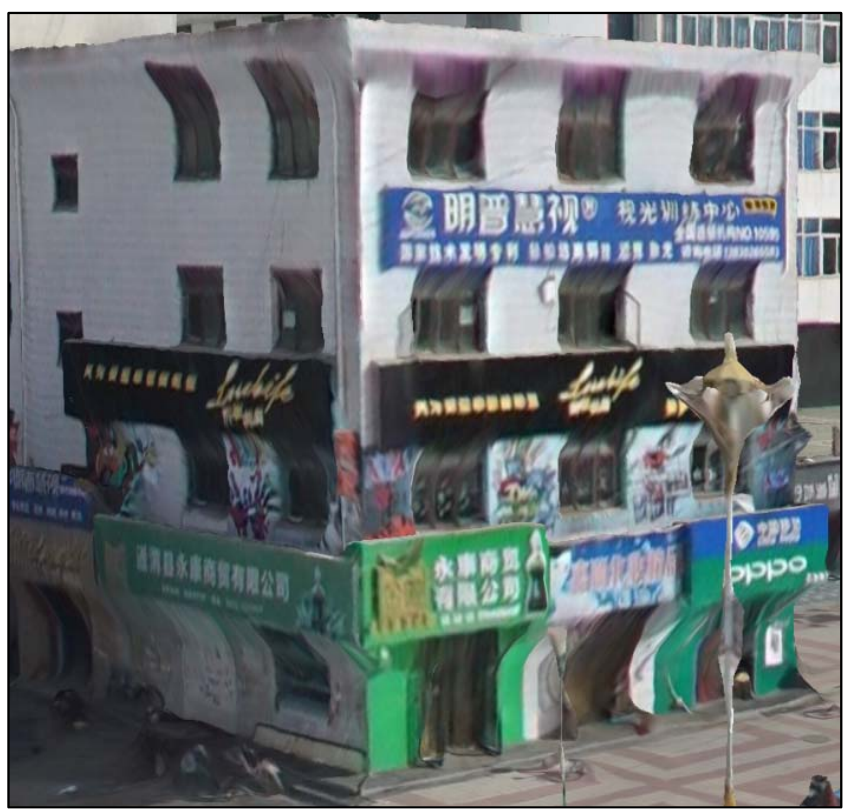

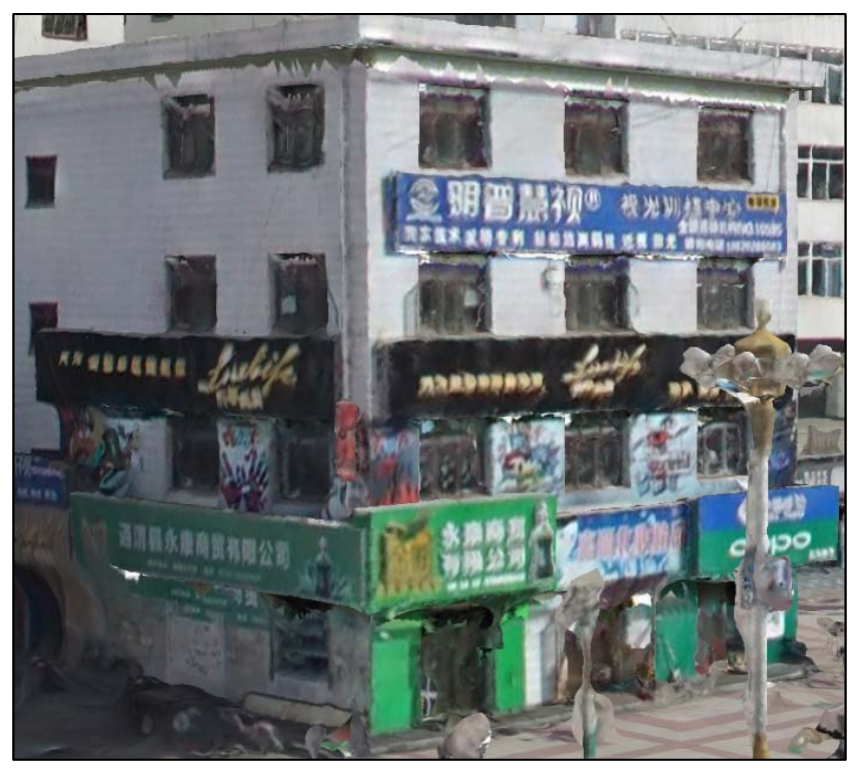

图2 融合车载点云前后建筑模型效果图, 左为融合前, 右为融合后 虽然融合数据有效解决了模型拉花问题, 但这种方法依然存在以下几 方面问题:

(1) 车载点云数据的精度高于倾斜摄影数据的精度, 在融合两种数据 时, 需要进行整体平差, 才能保障两种数据处于相同精度, 构建出完美模 型。否则, 构建的模型就会出现双层立面。ContextCapture Center软件没 有融合数据整体平差功能, 若两类数据精度相差过大, 就会出现双层立面 的问题。

(2) 在拉花现象的地方缺少倾斜纹理数据, 在纹理自动映射时没有相 应纹理数据, 从而导致模型拉花修复的地方呈现黑色。虽然可以通过后期 实地拍摄相应纹理进行修复, 但是会大大降低效率。本文提出一种研究方 向: 在车载点云数据处理时, 将与点云匹配的全景影像的RGB色彩赋予点云, 生成彩色点云, 在纹理映射的时候, 将彩色点云生成相应的纹理自动映射 到模型上, 从而解决模型拉花处无纹理的问题, 这需要研发相应软件。

(3) 本文采用的车载移动测量系统过于庞大, 只能在较宽道路上进 行数据采集, 这会在行道树或绿化带茂盛的地方造成点云数据缺失或密 度降低, 极大的影响了模型构建精度和完整性, 因此, 在今后作业中应选 用较小、较轻便的设备, 如摩托车式、自行车式、背包式三维激光扫描 测量系统。

\section{4 结语}

车载移动测量和倾斜摄影测量相结合的城市实景三维建模方法能有 效解决倾斜摄影测量建模近地面拉花问题, 具有精度高、成本低、增强模 型真实感的优势。虽然还存在双层立面、缺失纹理等问题, 但也不失为一 种高效建模的解决方案, 只需进一步深入研究, 就能实现城市建筑完整三 维模型的自动构建。

\section{[参考文献]}

[1]阙晓云,孙景振.LiDAR及倾斜摄影技术在数字实景城市模型中的应 用[J].测绘地理信息,2014,39(03):43-46.

[2]韩文泉.机载LiDAR点云和倾斜摄影影像数据融合处理技术流程 [J]. 城市勘测,2017,(05):17-21.

[3]吴建菲.基于Lidar数据和倾斜摄影的城市三维模型构建 [J].建材与 装饰,2018,(05):235. 